\title{
Multiliteracies in Music Education
}

\author{
Katie Tremblay-Beaton, \\ University of Toronto, Ontario Institute for Studies in Education, Canada
}

\begin{abstract}
This article calls into question the way in which music education is traditionally taught in North American schools. It looks at applying a framework of multiliteracies as way to move beyond direct instruction and incorporate student experience within the music classroom. The article draws parallels between music education and literacy education to demonstrate how a theory of multiliteracies can support musical processes, creativity, and student-centered meaning making within the context of music education.
\end{abstract}

\section{Introduction}

There are certain parallels that exist between music education and literacy education. Just as music making involves more than decoding signs and symbols, being literate involves much more than simply knowing how to operate the language system. It also includes the cultural and critical facets of knowledge integral to being literate Freire's view of literacy is one that is not exhausted merely by decoding the written word or written language, but rather anticipated by and extending into knowledge of the world [1], [2]. Literacy customarily challenges the learners with a group of codified situations so they will apprehend the word rather than learning to mechanically memorize or decode it [2], [1]. In this view, reading the world always precedes reading the word, and reading the word implies continually reading the world.

Unfortunately this is where the two fields of education encounter a shift in perspective. Historically, school performing ensembles have been modeled on their professional counterparts with a more authoritarian approach and focus on direct instruction [3]. The subject of that direct instruction has mostly likely been a focus on decoding the signs and symbols of traditional music notation. This is a direct contrast to Freire's [2] view in which we read the world before reading the world. In fact, it can be seen as the opposite, with this priority of reading notation at the forefront of traditional music education. North American music educators have become very good over the years at doing what we do - there is no disputing that. But we have not asked ourselves whether (or how) what we're doing is still adequate to the job at hand. We learn and teach the effective use of conventional tools instead of creative or alternative ways of achieving the tasks these tools were designed to execute. Meanwhile, the nature of music in its evolving practices and the ways it promises to enrich human lives has changed dramatically [4]. We cannot pretend to be relevant to the majority when what we offer is overwhelmingly a program reflective of our own values and our own interests attained because we are the ones who did achieve success in what has existed for so long at school music, all other values and interests being unworthy or even contemptible [5].

So if in the traditional model there is only one correct answer of how to interpret music, then what of the students who are reading their musical world in a way that does not reflect that singular interpretation? Perhaps music educators should look to Freire, to reading the world of their current classroom, and look to the literacy paradigm to embrace a more pluralistic pedagogy, such as multiliteracies.

\section{Multiliteracies in Music Education}

The theory of multiliteracies addresses increasing multiplicity and integration of significant modes of meaning making as well as the textual relationship between the visual, audio, and spatial [6]. Because multiliteracies focuses on the modes of representation much broader than language alone, it gives students the opportunity to engage with literacy in a way that is a dynamic process of transformation rather than a process of reproduction [6], [1].

Using multiliteracies as a framework for music literacy means we as music educators can shift our perspective of music as an autonomous idea and embrace the transformative meanings that our students bring to creating and interacting with music. Multiliteracies in music education gives space for students to incorporate their varied meaning-making practices from home, popular culture, technology, sports, and culture into making music in the classroom [7]. This is especially important because it opens students to the idea of creativity and transforming the world around them, thus redefining success in music education. Redefining success in turn leads to supporting more students in music and preparing them to be engaged in a positive relationship with music making. 


\section{Meaning Making}

The idea that musical meaning resides uniquely in musical objects bears little relation to music as it is actually practiced. Even within the Western classical tradition the exclusive concentration on musical works and the relegation of performance to subordinate status has resulted in a severe misunderstanding of what music is really about, and an impoverishment of our experience of it. For it is not true that performance takes place in order to present a musical work; it is the other way around. Musical works exist in order to give performers something to perform [8]. However, with the pressures of standardized testing and ministry initiatives, there is a current focus on product as evidence of learning in North American schooling [9], [10]. Freire labels this system of productoriented teaching as one of educational deposits in which students' work at storing the information given to them. The more completely they accept the passive role imposed on them, the more they tend to simply adapt to the world as it is and to the fragmented view of reality deposited in them. Freire acknowledged that literacy is deeply rooted in social and cultural issues, and that an autonomous model of literacy is promoted by product-oriented assessment.

The emphasis on the product over the process further supports a similar view in music education of privileging the musical work itself over the people engaged in creating it. When we read about the effect of music-the emotions it arouses, for example-what is really being talked about is the effect of a work of music. And further, what is meant is specifically the work's effect on an individual listener, not a composer, and certainly not on a performer. In fact, performers and performance are hardly ever mentioned in writings on the meaning of music. It seems as if a performer and his performance are thought of simply as the medium through which the musical work has to pass before it reaches its goalthe listener-and the more transparent the medium the better for the musical work [8].

Learning to read, in both a literacy sense and a musical one, must be seen as one aspect of the act of knowing with no one absolute Truth. It should be a creative act that is not exhausted merely by decoding the written word or written language, but rather anticipated by and extending into knowledge of the world [2]. Once we look past the idea of decoding and embrace reading for meaning as true understanding, we can reframe how we can transform ourselves with literacy [1].

\section{Creativity}

Creative thinking in music education allows students to move away from the traditional paradigm of music teaching and learning. Within this positivist framework there is only one correct interpretation of music and expectation of performance. How then can music educators make room for creativity in this arena? What criteria are we using to allow creativity to be a valid element of music education, equal to that of interpretation and replication? Applying a multi literacy model could give us insight into how to navigate this pluralistic world.

Canadian music education however has traditionally separated the elements of performance and composition [11]. The traditional methods used in performance education tend to exclude rather than include by creating hierarchies of achievement that underline power and control. Failure is regarded as wrong instead of as an opportunity for discovery [12]. Therefore performance, which is inherently replication focused with a specific intended outcome or correct answer, is privileged over composition. Composition however focuses on creating original music through composing or improvising, which means individuals may initiate new, original musical ideas that are developed and set into a context in new and original ways [13]. Without composition there would be no music to perform.

Education fails when it does not cultivate the creative processes yet while there is widespread support for the benefits of teaching students to think rationally, there's little understanding of how to teach students to think creatively [14]. The education system has developed an almost exclusive application of logic and reasoning to all subjects, however rational thought sorts and stores only the necessary information according to system; creative thought sort that stores the necessary, but also the casual, intuitive and inexplicable [14]. The very elements that are rejected in musical performance are celebrated in musical composition thus creating a paradox of what it means to fully engage with music making.

Music educators need to reframe the way in which we value all elements of music education. Both rational and creative thinking our fundamental skills that can be developed, however creative thinking is imaginative thinking [14]. Although a significant part of music education is instruction, the passing down of useful thinking that has been previously done, the deeper aims it to stimulate further thinking. Therefore it requires a creative response to all given material and making something new from what's given, even if what is given is within a performing context [15]. Students engage in musical thinking as they listen to, perform, and create music and this is central to one's ability to engage in and understand music [13]. All three musical processes require students to pull together the various aspects of their understanding of music and its contexts in order to understand the 
organization of sounds in relation to other contexts in which they occur.

All of these processes are considered creative processes [13]. Once we realize that problem-solving and decision-making require the cooperation of the two hemispheres of thought: the logical, and the creative, then we can begin to teach music education holistically in a way that focuses on the student instead of the subject [14]. Within literacy we see how student-centered teaching incorporates these dual aspects of both performance as reading and composition as writing and interpreting meaning.

\section{Student-Centered Teaching}

Within the context of literacy, the student is the subject. Instead of focusing on elements of language, the importance is placed on the process of learning to read and write as an act of knowing but also as creative act. The fact that he or she needs help learning how to do this, as in any pedagogical situation, does not mean that it annuls the students creativity and responsibility for constructing his or her own written language and reading this language [2]. This view of literacy is one that encompasses all facets of reading as one, including the creativity involved with interpretation of meaning, rather than trying to divide them into separate curriculum expectations.

Because of the interconnectedness of this version of literacy, it ultimately has to incorporate the individual ideologies present within the students in our classrooms. We need to regard this ideology as the site of tension between authority and power on the one hand and resistance and creativity on the other. This tension operates through the medium of a variety of cultural practices, including particularly language and literacy. It is in this sense that it important to approach the study of literacy in terms of an explicit ideological model. We can't downplay the creativity and cultural concerns of people being taught to read and write and the impact literacy on the individual [16]. If we were to approach music literacy from this ideological model then we would be redefining what counts as legitimate musics and ways of interacting with these musics on a fundamental and deeply personal level.

Part of the transformative nature of literacy as an ideological model is that it is accessible to all students. A transformative literacy allows the participants to focus on modes of representation that are broader than language alone and focus on how cultural and linguistic diversity also includes other modes of meaning in our dynamic representational resources constantly being remade by their users as they work to achieve their various cultural purposes [6]. Therefore renaming the traditional literacy pedagogy allows for greater interpretation of ideas and encourages students to work in a new framework, including one that does not already assume their failure.

Similarly, it would be illogical and potentially harmful to insist that there is one music education methodology, or one set of national curriculum standards that are valid for every teacher and learner in every situation [17]. Assuming that all students fit the criteria outlined by a unified educational model of a performance-based program fails to provide what's required to empower students' musical growth and full human flourishing. When a miseducative musician overemphasizes musical details at the expense of educational matters, then music 'learning' is reduced to training student' technical, notational, and aural skills, or stuffing learners' heads with abstract concepts about music [17]. The result of an overload on notation and theory in a primarily performance-based curriculum only supports the likelihood that that learners will end up knowing how to name notes on the stave or on an instrument, or knowing the names of musical procedures and elements, but not knowing what to do with them [18]. In order for there to be true musical understanding for each student, they need to conceptualize music in a way that is unique and meaningful to them [13]. This explains why the interpersonal connection between the student and the experience of making music is so crucial.

When students are permitted to think freely and sound to generate and develop their own material, they feel a strong sense of ownership of the musical work they are producing. When students have ownership of the music they are creating, the experience becomes meaningful to them-connect to their lives. When students are permitted to initiate and develop original musical ideas in the music classroom, they know that their ideas are valued in that classroom. The music learning experience becomes personally valuable and meaningful to them [13].

In order for students to be successful, we need to create a vision of success that is not defined exclusively in economic terms and that has embedded within it a critique of hierarchy and economic injustice. We must create a space where ordinary teachers working with ordinary students can create extraordinarily powerful learning opportunities when they step outside the frame of top-down one-size-fits-all mandates and connect imaginatively at a personal level with students and communities [19], [1]. These learning opportunities are occurring in literacy education. There is a possibly within music education if we as educators reframe our perspective of what music education should look like in our classrooms and make way for the same transformative learning opportunities that are occurring in literacy education. 


\section{References}

[1] Cope, B., \& Klantzis, M. (2009). "Multiliteracies": New literacies, new learning. Pedagogies: An international journal. Vol. 4, 164-195.

[2] Freire, P. (1987). The importance of the act of reading. In. P. Freire and D. Macedo (Eds.), Literacy: Reading the word and the world. South Hadley, MA: Bergin and Garvey. p.5-11

[3] Wasiak, E. (2013). Teaching Instrumental Music in Canadian Schools. Don Mills, ON: Oxford University Press.

[4] Bowman, W. (2012) Manitoba’s success story: What constitutes successful music education in the twenty-first century? In C. Beynon \& K. Veblen (Eds.) Critical perspectives in Canadian music education. p.49-69. Canada: Wilfred Laurier University Press.

[5] Reimer, B. (2009). Seeking the Significance of Music Education: Essays and Reflections. Lanham, MD: R and L Professional Education.

[6] New London Group (1996). “A pedagogy of multiliteracies: Designing social futures.” Harvard Educational Review, 66, 60-92.

[7] Benedict, C. (2012) "Critical and Transformative Literacies: Music and General Education.” Theory into Practice. 51:152-158

[8] Small, C. (1998) Musicking. Prelude: Music and Musicking. Wesleyan University Press, Hanover, NH.

[9] Jocson, K. \& Cooks, J. (2011). Writing as a Site of Struggle: Popular Culture, Empowerment, and Politics of (In) Visibility. In V. Kinloch (Ed.), Urban Literacies:Critical Perspectives on Language, Learning, and Community. New York: Teachers College Press.

[10] Freire, P. (1970). Pedagogy of the Oppressed. New York, NY. The Continuum International Publishing Group. Chapter 2.

[11] Ontario Arts Curriculum (2009). Ontario Ministry of Education.https://www.edu.gov.on.ca/eng/curriculum/elem entary/arts18b09curr.pdf

[12] Wiegold, P. Thus Far, No Further...? Formal Learning-Creative Learning. In Bartel, L. (2002) Creativity and Music Education, Canadian Music Educators Association, Toronto; ON

[13] Wiggins, J. Creative Processes as Meaningful Musical Thinking. In Bartel, L. (2002) Creativity and Music Education, Canadian Music Educators Association, Toronto; ON

[14] Sullivan, T. Creativity in Action. In Bartel, L. (2002) Creativity and Music Education, Canadian Music Educators Association, Toronto; ON
[15] Goodkin, D. Creative Education. In Bartel, L. (2002) Creativity and Music Education, Canadian Music Educators Association, Toronto; ON

[16] Street, B. (2011) Introduction: The New Literacy Studies. In Lankshear and Knobel, New Literacies: Everyday Practices and Social Learning. New York, McGraw Hill.

[17] Elliot, D. and Silverman, M. (2015) Music Matters: A Philosophy of Music Education Second Edition. New York, NY. Oxford University Press.

[18] Green, L. (2002) How Popular Musicians Learn; A Way Ahead for Music Education. Burlington, VT: Ashgate Publishing Company.

[19] Cummins, J. (2005) in K.Pahl and J.Rowseu, Literacy and Education: Understanding the New Literacy Studies in the Classroom. Los Angelas, CA; Sage Publications. 